Jurnal Kepelatihan Olahraga, Universitas Pendidikan Indonesia

Jurnal Kepelatihan

Olahraga

Journal homepage: http://ejournal.upi.edu/index.php/JKO

Volume 11, No. 2, September 2019

p-ISSN 2086-339X / e-ISSN 2657-1765

\title{
Pengaruh Media Papan Luncur dan Pull Buoy Pola Metode Drill terhadap Hasil Belajar Teknik Dasar Renang Gaya Bebas
}

Agung Rizkiyansyah ${ }^{1 *}$, Boyke Mulyana

${ }^{1}$ Pendidikan Kepelatihan Olahraga, Fakultas Pendidikan Olahraga dan Kesehatan, Universitas Pendidikan Indonesia, Bandung, Indonesia

*cragung0@gmail.com

\begin{abstract}
A B S T R A C T S
The purpose of this study is: (1) To find out the effect kick board tools in the drill method pattern towards the results of learning freestyle swimming techniques, (2) To find out the effect pull buoy tools in the drill method pattern towards the results of learning freestyle swimming techniques, (3) To find out which influences are more effective than kick board and pull buoy tools in the drill method pattern towards the results of learning freestyle swimming techniques. This research method uses experiments with rating scale techniques. The study population was 14 members. The research sample used Purposive Sampling. The research instrument uses: observation test sheet for students regarding the format for assessing the basic motion coordination of freestyle swimming and research documentation. In this study the authors analyzed the data with the help of the SPSS 17 program. The results of testing the hypothesis of this study proved that, use tools kickboard it can improve the learning outcomes of basic freestyle swimming techniques, use tools pull buoy it can improve the learning outcomes of basic freestyle swimming techniques, using both media together can effectively improve the learning outcomes of basic freestyle swimming techniques. In its use can be tailored to the training needs.
\end{abstract}

(C) 2019 Tim Pengembang Jurnal Kepelatihan Olahraga

\begin{tabular}{l}
\hline A B S T R A K \\
Tujuan penelitian ini adalah: (1) Untuk mengetahui pengaruh media papan \\
luncur pada pola metode drill terhadap hasil belajar teknik dasar renang \\
gaya bebas, (2) Untuk mengetahui pengaruh media pull buoy pada pola \\
metode drill terhadap hasil belajar teknik dasar renang gaya bebas, (3) \\
Untuk mengetahui manakah pengaruh yang lebih efektif dari media papan \\
luncur dan pull buoy pola metode drill terhadap hasil belajar teknik dasar \\
renang gaya bebas. Metode penelitian ini menggunakan eksperimen \\
dengan teknik rating scale. Populasi penelitian sebanyak 14 anggota. \\
Sampel penelitian menggunakan Purposive Sampling. Instrumen \\
penelitian menggunakan: lembar tes observasi untuk mahasiswa mengenai \\
format penilaian koordinasi gerak dasar renang gaya bebas dan \\
dokumentasi penelitian. Hasil pengujian hipotesis penelitian ini terbukti \\
\hline
\end{tabular}

\begin{tabular}{l}
\hline \multicolumn{1}{c}{ A R T I C L E I N F O } \\
\hline Article History: \\
Received 15 Mei 2019 \\
Revised 12 June 2019 \\
Accepted 29 July 2019 \\
Available online 30 Sept 2019 \\
Keyword: \\
Kick Board, Pull Buoy, Drill \\
Method, and Basic Freestyle \\
Swimming Technique. \\
\\
Riterima 15 Mei 2019 \\
Direvisi 12 Juni 2019 \\
Tersedia online 30 Sept 2019 \\
Kata Kunci: \\
Retode Drill, dan Teknik Dasar \\
\hline I Naya Bebas. \\
\hline
\end{tabular}


bahwa, menggunakan media papan luncur tersebut dapat meningkatkan hasil belajar teknik dasar renang gaya bebas, menggunakan media pull buoy tersebut dapat meningkatkan hasil belajar teknik dasar renang gaya bebas, dan menggunakan kedua media tersebut sama-sama efektif dapat meningkatkan hasil belajar teknik dasar renang gaya bebas. Dalam penggunaanya dapat disesuaikan dengan kebutuhan latihan.

\section{PENDAHULUAN}

Renang adalah olahraga yang melombakan kecepatan atlet renang dalam berenang. Gaya renang yang diperlombakan adalah gaya bebas, gaya kupu-kupu, gaya punggung, dan gaya dada. Ada pula menurut Badruzaman (2015, hlm. 3) mendefinisikan renang secara umum adalah upaya mengapungkan atau mengangkat tubuh ke atas permukaan air. Sedangkan menurut Abdullah (dalam Badruzaman, 2015, hlm. 4) menyatakan bahwa renang adalah suatu jenis olahraga yang dilakukan di air, baik di air tawar maupun di air asin atau laut.

Dari pengertian di atas penulis berpendapat bahwa renang adalah salah satu jenis olahraga yang bisa di lakukan oleh anak-anak sampai orang dewasa dimana perenang berupaya mengapung dan mengangkat tubuh agar tidak tenggelam yang bisa dilakukan di air tawar maupun maupun di air asin (lautan).

Renang sangat dikenal di lingkungan masyarakat yang luas, khususnya di bangku perkuliahan. Pembelajaran renang di kampus sangat penting diajarkan khususnya untuk mahasiswa tingkat awal yang masih belum mengetahui renang secara keseluruhan, Mahasiswa khususnya FPOK dituntut agar mengenal, belajar, dan mengembangkan tentang olahraga aquatik yang memasyarakat ini. Salah satu proses yang harus diperhatikan dalam pembinaan ialah proses pelatihan, menurut Harsono (1988, hlm. 101) menyatakan bahwa latihan adalah proses yang sistematis dari berlatih atau bekerja, yang dilakukan secara berulang-ulang, dengan kian hari kian menambah jumlah beban latihan atau pekerjaannya. Sedangkan menurut Dikdik (2008, hlm. 4) bahwa latihan adalah proses aktivitas tubuh yang dilakukan secara sistematis, bertahap, terusmenerus, dan bebas aktivitasnya meningkat teratur.

Dari pernyataan para ahli di atas dapat disimpulkan bahwa latihan teratur secara berulang-ulang dapat memberikan dampak gerakan-gerakan yang semula sukar dilakukan menjadi semakin mudah, otomatis dan reflektif pelaksanaannya sehingga menghemat energi.

Agar proses pelatihan tersebut sistematis dan meningkatnya teratur, perlu adanya metode latihan drill pada teknik gerak dasar renang gaya bebas ini, karena metode drill yang dilakukan secara rutin dan berulang-ulang memudahkan mahasiswa untuk mengingat setiap gerakan yang di berikan dalam proses latihan. Menurut Sudjana (2002, hlm. 86) Metode drill merupakan metode yang dapat diartikan sebagai suatu cara mengajar dimana siswa melaksanakan kegiatankegiatan latihan agar siswa memiliki ketangkasan atau keterampilan yang lebih tinggi dari pada yang telah dipelajari sebelumnya, latihan yang 
praktis, mudah dilakukan serta teratur dalam melaksanakannya, membina anak dalam meningkatkan penguasaan ketempilan itu dengan sempurna.

Penyelenggaraan Unit Kegiatan Mahasiswa Aquatik cukup lama terbentuk dan UKM ini mendapat perhatian yang baik dari dosen dan pihak kampus. Akan tetapi dari UKM aquatik ini belum ada pelatih khusus yang memungkinkan penyelenggaraan UKM aquatik menjadi bagian signifikan untuk mendorong mahasiswa menjadi lebih baik dan terarah.

Berdasarkan wawancara dengan bagian kepala Pembinaan Prestasi, menurut riset pembinaan renang di UKM ini sedikit menurun dan belum tersampaikan secara maksimal, karena Pelatih yang ada di UKM ini belum memiliki keahlian khusus dalam melatih renang artinya belum mengetahui metode pelatihan seperti apa yang baik dan struktur, serta kurangnya sarana prasarana menjadi salah satu kendala terhadap pelatihan renang tersebut. Sehingga permasalahannya berujung pada mahasiswa yaitu dalam mempelajari gerak dasar renang khususnya di gaya bebas, mahasiswa hanya sekedar bisa melakukan renang gaya bebas tanpa mengetahui tahapan posisi tubuh, gerakan kaki, gerakan tangan, pengambilan nafas, dan koordinasi gerakan yang benar dan efektif.

Agar penyampaian teknik dasar renang gaya bebas dapat meningkat, perlunya media atau alat bantu untuk menunjang keberhasilan teknik dasar renang gaya bebas.

Menurut Subagyo dan Sismadiyanto, (2009, hlm. 53) menyatakan bahwa menggunakan bantuan alat, posisi badan perenang di dalam air dapat membantu posisi tubuh menjadi Stream
Line (datar) sehingga mendapatkan bentuk yang mempunyai tahanan yang lebih kecil. Sedangkan ada pendapat lain Menurut Megasari (2012, hlm. 5) bahwa penggunaan alat bantu papan dalam pembelajaran renang dapat meningkatkan keterampilan renang gaya bebas.

Dari pernyataan diatas dapat disimpulkan bahwa penggunaan alat bantu berupa kaki katak (flipper), pelampung, paddle, pull buoy sangat membantu daya apung sehingga dapat stream line (datar) dan memudahkan untuk menguasai teknik dasar renang gaya bebas, dengan demikian perhatian belajar renang bisa terpusat pada teknik gerakan kaki dan gerakan lengan. Artinya, dalam penelitian ini digunakan media berupa papan luncur dan pull buoy untuk membantu meningkatkan hasil belajar gerak dasar teknik renang gaya bebas.

Gaya bebas merupakan gaya renang yang tercepat dibandingkan dengan ketiga gaya lainnya, karena gaya renang ini mempunyai koordinasi gerak yang baik dan hambatannya paling minim. Ciri khas dari gaya bebas adalah gerakan lengannya berputar mirip dengan balingbaling pesawat udara, dan gerakan tungkai kakinya turun naik secara menyilang. Menurut Ernest W. Maglischo (2003, hlm. 95) mengungkapkan bahwa Gaya bebas merupakan gaya yang tercepat dan berdasarkan gaya ini pula kehebatan berenang akan dinilai bagaimana mulusnya dan mudahnya berenang gaya bebas. Didalam renang gaya bebas yang perlu kita pelajari yaitu bagaimana cara posisi tubuh didalam air, gerakan kaki, gerakan tangan, bernapas dan gerakan koordinasi.

Berdasarkan uraian latar belakang di atas, maka penulis tertarik untuk melakukan 
peneltian tentang "Pengaruh Media Papan Luncur dan Pull Buoy Pola Metode Drill Terhadap Hasil Belajar Teknik Gerak Dasar Renang Gaya Bebas."

\section{METODE}

Penelitian ini menggunakan metode eksperimen dengan desain penelitian one groups pretest-posttest.

Teknik pengambilan sampel dalam penelitian ini adalah purposive sampling. Peneliti cenderung menggunakan metode eksperimen dan scala rating. Program latihann (treatment) ini diberikan selama 5 minggu dengan total 16 kali pertemuan $3 \mathrm{kali} /$ minggu. Dengan tata cara peserta sebelumnya melakukan pemanasan, kemudian berbaris dan diberi pengarahan. Tes dilakukan dengan menggunakan dinding kolam untuk loncatan renang. Selanjutnya, peserta bergiliran dengan jumlah satu orang melakukan tes renang gaya bebas 25 meter untuk melihat keterampilan renang gaya bebas sehingga tidak harus mencapai 25 meter karena keterampilan sudah dapat dilihat. Pelaksanaan dilakukan oleh tiga orang pelatih renang untuk menilai teknik dasar masing-masing peserta, agar setiap pengajar dapat fokus pada pemberian nilai. Penilai hanya memberikan tanda $(\sqrt{ })$ pada setiap skor.

\subsection{Subjek Penelitian}

Populasi dalam penelitian ini adalah anggota Unit Kegiatan Mahasiswa Aquatik, yang berjumlah 48 orang. Subjek penelitian adalah perenang pemula yang berjumlah 14 orang dari perenang (UKM) Aquatik.

\subsection{Prosedur Penelitian}

Tahapan penelitian yang dilakukan adalah sebagai berikut: (1) Melakukan test awal (pretest). (2) Setelah itu data test diranking. (3) Setelah tersusun, sampel dibagi menjadi 2 kelompok. (4) Melakukan perlakuan (treatment) untuk kelompok A dengan menggunakan media papan luncur, dan B dengan menggunakan media pull buoy. (5) Masing-masing kelompok menjalani kegiatan eksperimen selama waktu pelatihan tersebut ditetapkan. (6) Setelah menjalani perlakukan (treatment) kemudian dilakukan test akhir (post-test). (7) Setelah memperoleh data awal dan akhir, selanjutnya diolah dan dianalisis secara statistic sehingga hasilnya dapat ditafsirkan dan dijadikan acuan dalam pengambilan kesimpulan.

\section{HASIL PENELITIAN}

Hasil Perhitungan dan Uji Signifikansi dapat dilihat pada Tabel 3.1.

Tabel 3.1 Paired Sample T-Test

\begin{tabular}{cccc}
\hline Kelompok & t hitung & $\mathrm{t}$ tabel & Kesimpulan \\
\hline $\begin{array}{c}\text { Tes Awal - } \\
\text { Akhir Papan } \\
\text { Luncur }\end{array}$ & 11,35 & 0,000 & Ditolak \\
\hline $\begin{array}{c}\text { Tes Awal - } \\
\text { Akhir Pull } \\
\text { Buoy }\end{array}$ & 11,099 & 0,000 & Ditolak \\
\hline
\end{tabular}

Berdasarkan data diatas penulis menggunakan Uji T Paired pada kelompok A dan kelompok B untuk mengetahui signifikan atau tidaknya data. Setelah dilakukan uji signifikansi T hitung dari kelompok A sebesar 11,35 dengan df 6 pada taraf $\alpha 0,05$ maka $\mathrm{T}$ tabel $=0,000$ maka T hitung kempok A 11,35 > 0,000 yang berarti terdapat pengaruh yang signifikan. 
Sedangkan pada kelompok B sebesar 11,099 dengan df 6 pada taraf $\alpha 0,05$ maka $\mathrm{T}$ tabel $=$ 0,000 maka T hitung kempok A 11,099 > 0,000 yang berarti terdapat pengaruh yang signifikan pada kelompok B.

Grafik 3.1. Rata-rata selisih skor tes awal dan tes akhir kelompok dengan papan luncur dan pull buoy

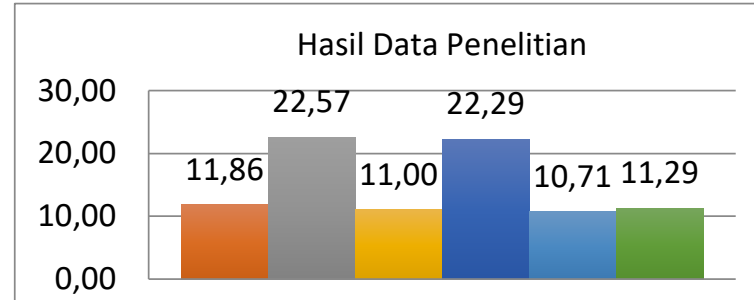

Tes Awal PL $\square$ Tes Akhir PL $\square$ Tes Awal PB

Tes Akhir PB $\quad$ Gain PL $\quad$ Gain PB

Grafik 3.1 menggambarkan bahwa, perbedaan media papan luncur dan pull buoy pada saat pre-test dan post-test dapat disimpulkan bahwa setelah melakukan treatment penggunaan papan luncur dan pull buoy sama efektifnya karena memberikan pengaruh yang signifikan terhadap hasil belajar teknik dasar renang gaya bebas. Media papan luncur dan pull buoy ini dirasa cocok karena harus mempelajari teknik dasar gaya bebas bagian demi bagian.

\section{PEMBAHASAN}

Dari data yang diperoleh dari hasil pretest dan posttest dapat dibandingkan hasilnya bahwa, penggunaan media papan luncur sangat dianjurkan untuk tahap awal bagi perenang pemula karena diberikan latihan dengan gerakan renang gaya bebas yang paling mudah dulu contohnya seperti meluncur, pengambilan nafas hingga gerakan tersulit. metode ini diberikan agar dapat menguasai teknik dengan sempurna. Kemudian, menurut Bahagia dan Mujianto
(2009, hlm. 203) bahwa pelampung merupakan sebuah media atau alat untuk membantu dalam pembelajaran renang pemula, atau untuk melakukan aktivitas berenang dengan hanya menggunakan gerakan lengan saja atau gerakan kaki saja.

Kemudian, untuk media pull buoy juga banyak membantu tercapainya suatu gerakan yang diharapkan dari suatu gerak pada renang gaya bebas. Menurut Subagyo dan Sismadiyanto (2009, hlm. 53) bahwa penggunaan alat bantu berupa kaki katak (flipper), pelampung (float), paddle, pullbuoy untuk siswa sangat membantu daya apung sehingga memudahkan siswa untuk menguasai teknik dasar renang

Adapun hasil penerapan dari kedua media tersebut mempunyai sama efektifnya untuk peningkatan hasil belajar teknik dasar renang gaya bebas yang signifikan, akan lebih baik lagi jika yang digunakan untuk perenang pemula itu menggunakan papan luncur terlebih dahulu karena memberikan daya apung dan kemudahan untuk menguasai teknik lengan saja atau kaki saja, lalu dilanjutkan dengan pull buoy agar dapat membantu ke teknik gaya bebas yang tersulit.

Adapun hal lain yang dapat diperhatikan setelah treatment dari kedua kelompok tersebut mahasiswa lebih termotivasi ingin belajar renang lebih banyak lagi apalagi dengan gerakan variasi artinya selain mereka belajar berenang mereka mendapatkan ilmu wawasan tentang renang.

Pada pelaksanaan latihan dimulai dari hal dasar yaitu pengambilan nafas dan mengurangi rasa ketakutan di air atau adaptasi. Setelah itu di pelajari bagaimana gerakan kaki yang efektif dan efisien. Setelah kaki berlanjut pada gerakan 
lengan yang efektif dalam gerakan rotasi lengan dengan dilanjutkan bagaimana pengambilan nafas yang baik. Kemudian diakhiri dengan gerak keseluruhan atau koordinasi lengan, kaki, dan napas. Untuk keempat bagian latihan tersebut dilakukannya secara berulang-ulang dalam setiap bagian hingga lancar melakukannya dan di variasikan gerakkannya agar latihan tidak membosankan.

Dalam hasil pengolahan data dalam penelitian ini tidak mengalami kekeliruan, maka hasil latihan ini menunjukan adanya efektifitas dari kedua kelompok dengan media papan luncur dan pull buoy pola metode drill yang diteliti serta dapat dimanfaatkan untuk kedepannya. Adapun hasil dari pengolahan data dan analisis yang diperoleh sudah terlihat bahwa tidak terdapat perbedaan yang signifikan antara kelompok yang menggunakan papan luncur dan pull buoy dalam peningkatan hasil belajar teknik dasar renang gaya bebas.

Hasil pembahasan yang telah dipaparkan peneliti dapat memberikan gambaran bahwa dengan menggunakan kedua media tersebut dapat meningkatkan hasil belajar teknik dasar renang gaya bebas, dalam penggunaannya dapat disesuaikan dengan kebutuhan latihan diperlukan.

\section{KESIMPULAN DAN SARAN}

Berdasarkan hasil pengolahan dan analisis data, maka kesimpulan dari penelitian Pengaruh Media Papan Luncur dan Pull Buoy Pola Metode
Drill Terhadap Teknik Dasar Renang Gaya Bebas adalah sebagai berikut : (1) Terdapat pengaruh yang signifikan dari penerapan media papan luncur pada pola metode drill terhadap hasil belajar teknik dasar renang gaya bebas. (2) Terdapat pengaruh yang signifikan dari penerapan media pull buoy pada pola metode drill terhadap hasil belajar teknik dasar renang gaya bebas. (3) Kedua media tersebut yaitu media papan luncur dan pull buoy pola metode drill sama-sama dapat meningkatkan hasil belajar teknik dasar renang gaya bebas.

Atas dasar hasil dari penelitian ini, maka saran yang dapat dikemukakan adalah sebgai berikut : (1) Tanpa mengabaikan aspek yang lain, metode/bentuk latihan menggunakan media papan luncur dan pull buoy perlu diberikan kepada perenang dalam proses latihan, terutama dalam meningkatkan keterampilan renang gaya bebas ataupun gaya renang yang lain serta pengembangkan pada perenang pemula. (2) Perlu dilakukan penelitian lebih lanjut mengenai metode latihan yang dapat memberikan pengaruh dalam pengembangan olahraga renang, dengan lebih memperluas ruang lingkup penelitian seperti pada aspek fisik, teknik, taktik, dan psikologis, agar hasil yang diharapkan bisa tercapai dengan tepat. (3) Bagi Unit Kegiatan Mahasiswa diharapkan selalu melakukan secara maksimal dengan fasilitas yang memadai begitu juga dengan proses latihannya degan bersungguh-sungguh dan maksimal. 


\section{DAFTAR PUSTAKA}

Arikunto. (2002). Prosedur Penelitian Ilmiah Suatu Pendekatan Praktis. Jakarta: P.T. Rineka Cipta.

Badruzaman. (2015). Renang untuk Pemula, Lanjutan dan Penyempurnaan. Bandung: FPOK UPI Bandung.

Bahagia, Y. \& Mujianto, S. (2009). Media dan Alat Pembelajaran Penjas. Jurusan Pendidikan Olahraga Fakultas Pendidikan Olahraga dan Kesehatan Universitas Pendidikan Indonesia.

Guzman, J.Ruben. (1998). Swimming Drills for Every Stroke. United States of Amerika.

Harsono. (1988). Coaching dan Aspek-Aspek Psikologis dalam Coaching. Jakarta: CV.Tambak Kusuma.

Levinus, Paulus, Dikdik Zafar Sidik. (2016). Pembinaan Kondisi Fisik. Bandung: FPOK UPI.

Maglischo, Ernest W. (2003). Swimming Fastest. Canada: Human Kinetics.

Megasari, Kikit. (2012). Penggunaan Alat Bantu Papan Pelampung Dalam Upaya Meningkatkan Hasil Belajar Renang Gaya Bebas : Ptk Pada Siswa Kelas X Smk Negeri 3 Cimahi, [Online], Diakses : http://repository.upi.edu/10535/.

Subagyo dan Sismadiyanto. (2009). Peningkatan Hasil Belajar Renang Gaya Crawl Melalui Multi.Stroke Method A Flipper-Float Method, Journal: Ilmu Keolahragaan, 2 , 41-54, [Online], Diakses : http://staff.uny.ac.id/sites/default/files. 


\section{LAMPIRAN 1}

Program Latihan dengan Menggunakan Media Papan Luncur dan Pull Buoy Pola Metode Drill Terhadap Hasil Belajar Teknik Dasar Renang Gaya Bebas

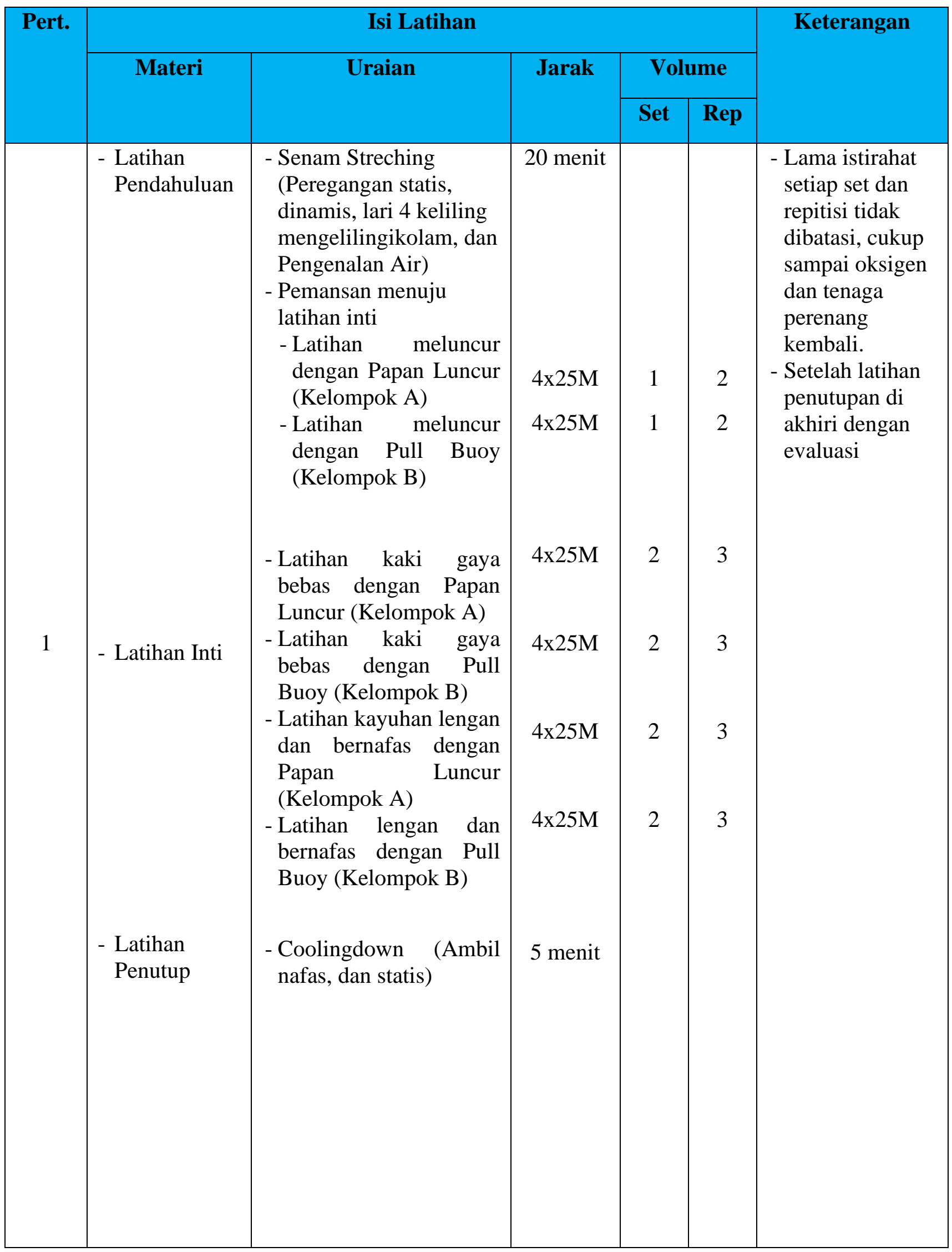




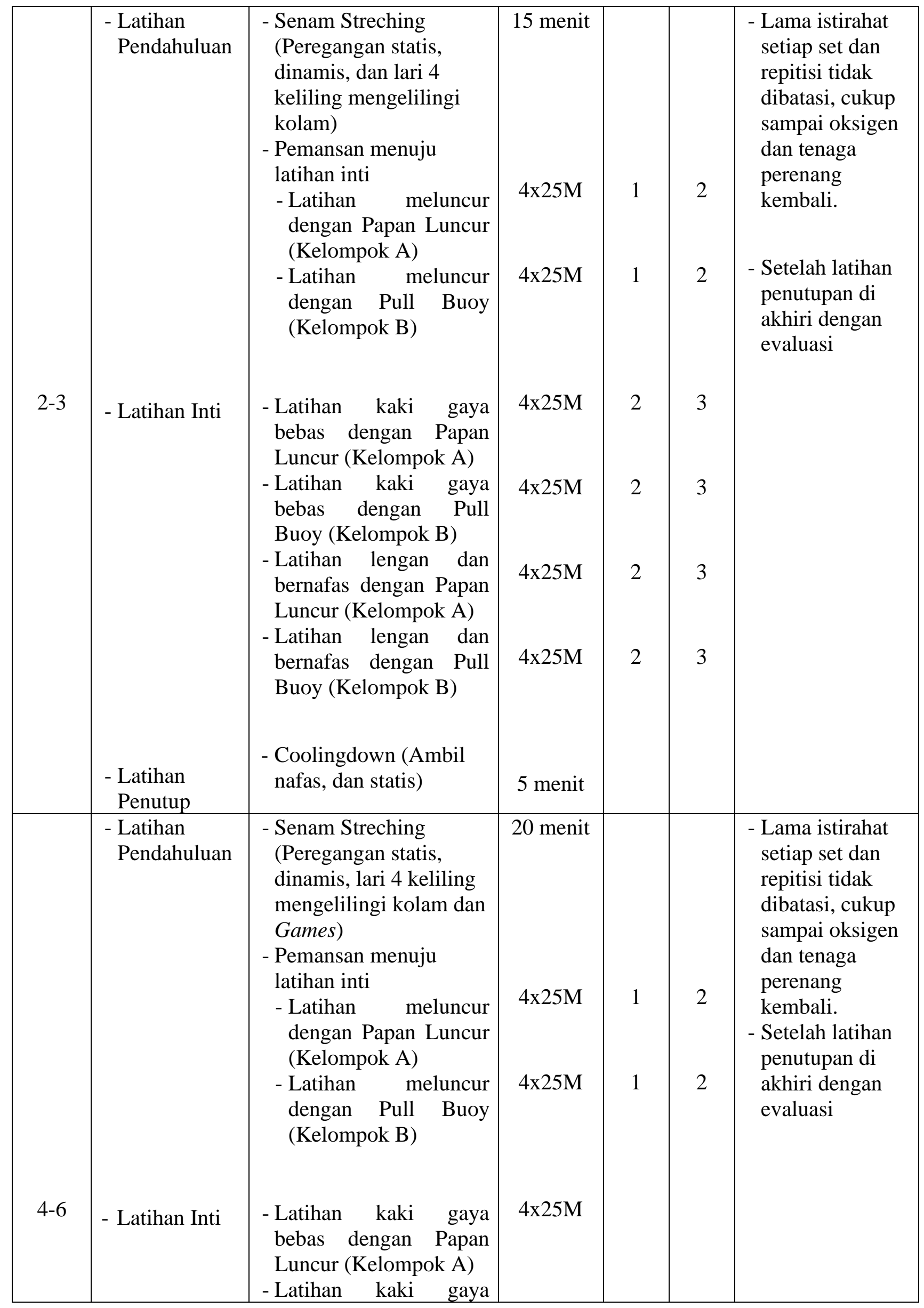




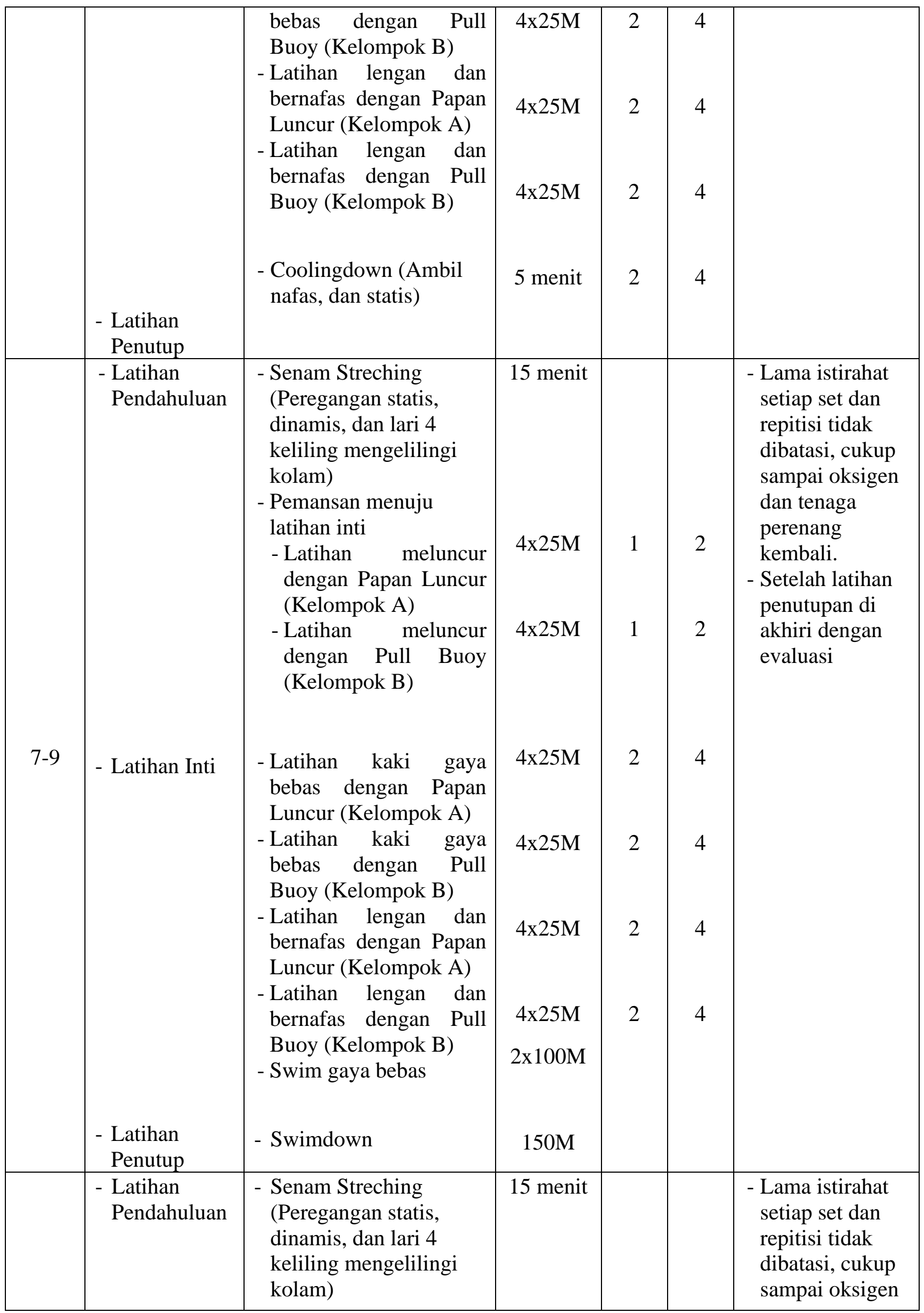




\begin{tabular}{|c|c|c|c|c|c|c|}
\hline \multirow{3}{*}{$10-12$} & \multirow{3}{*}{ - Latihan Inti } & $\begin{array}{l}\text { - Pemansan menuju } \\
\text { latihan inti } \\
\text { - Latihan meluncur } \\
\text { dengan Papan Luncur } \\
\text { (Kelompok A) } \\
\text { - Latihan meluncur } \\
\text { dengan Pull Buoy } \\
\text { (Kelompok B) }\end{array}$ & $4 \times 25 \mathrm{M}$ & 1 & 3 & $\begin{array}{l}\text { dan tenaga } \\
\text { perenang } \\
\text { kembali. } \\
\text { - Setelah latihan } \\
\text { penutupan di } \\
\text { akhiri dengan } \\
\text { evaluasi }\end{array}$ \\
\hline & & $\begin{array}{l}\text { - Latihan kaki gaya } \\
\text { bebas dengan Papan } \\
\text { Luncur (Kelompok A) } \\
\text { - Latihan kaki gaya } \\
\text { bebas dengan Pull } \\
\text { Buoy (Kelompok B) } \\
\text { - Latihan lengan dan } \\
\text { bernafas dengan Papan } \\
\text { Luncur (Kelompok A) } \\
\text { - Latihan lengan dan } \\
\text { bernafas dengan Pull } \\
\text { Buoy (Kelompok B) } \\
\text { - Swim gaya bebas }\end{array}$ & $\begin{array}{l}4 \times 25 \mathrm{M} \\
4 \times 25 \mathrm{M} \\
4 \times 25 \mathrm{M} \\
4 \times 25 \mathrm{M} \\
3 \times 100 \mathrm{M}\end{array}$ & 2 & 4 & \\
\hline & & - Swimdown & $150 \mathrm{M}$ & & & \\
\hline $13-15$ & $\begin{array}{l}\text { - Latihan } \\
\text { Pendahuluan }\end{array}$ & $\begin{array}{l}\text { - Senam Streching } \\
\text { (Peregangan statis, } \\
\text { dinamis, dan lari } 4 \\
\text { keliling mengelilingi } \\
\text { kolam) } \\
\text { - Pemansan menuju } \\
\text { latihan inti } \\
\text { - Latihan kaki gaya } \\
\text { bebas dengan Papan } \\
\text { Luncur (Kelompok A) } \\
\text { - Latihan kaki gaya } \\
\text { bebas dengan Pull } \\
\text { Buoy (Kelompok B) } \\
\text { - Latihan lengan dan } \\
\text { bernafas dengan } \\
\text { Papan Luncur } \\
\text { (Kelompok A) } \\
\text { - Latihan lengan dan } \\
\text { bernafas dengan Pull } \\
\text { Buoy (Kelompok B) } \\
\text { - Swim gaya bebas } \\
\text { - Swimdown }\end{array}$ & $\begin{array}{l}4 \times 25 \mathrm{M} \\
4 \times 25 \mathrm{M} \\
4 \times 25 \mathrm{M} \\
4 \times 25 \mathrm{M} \\
3 \times 100 \mathrm{M} \\
150 \mathrm{M}\end{array}$ & 3 & 4 & $\begin{array}{l}\text { - Lama istirahat } \\
\text { setiap set dan } \\
\text { repitisi tidak } \\
\text { dibatasi, cukup } \\
\text { sampai oksigen } \\
\text { dan tenaga } \\
\text { perenang } \\
\text { kembali. } \\
\text { - Setelah latihan } \\
\text { penutupan di } \\
\text { akhiri dengan } \\
\text { evaluasi }\end{array}$ \\
\hline
\end{tabular}




\begin{tabular}{|c|c|c|c|c|c|c|}
\hline & Penutup & & & & & \\
\hline 16 & $\begin{array}{l}\text { - Latihan } \\
\text { Pendahuluan }\end{array}$ & $\begin{array}{l}\text { - Senam Streching } \\
\text { (Peregangan statis, } \\
\text { dinamis, dan lari } 4 \\
\text { keliling mengelilingi } \\
\text { kolam) } \\
\text { - Pemansan menuju } \\
\text { latihan inti } \\
\text { - Latihan kaki gaya } \\
\text { bebas dengan Papan } \\
\text { Luncur (Kelompok A) } \\
\text { - Latihan kaki gaya } \\
\text { bebas dengan Pull } \\
\text { Buoy (Kelompok B) } \\
\text { - Latihan lengan dan } \\
\text { bernafas dengan } \\
\text { Papan Luncur } \\
\text { (Kelompok A) } \\
\text { - Latihan lengan dan } \\
\text { bernafas dengan Pull } \\
\text { Buoy (Kelompok B) }\end{array}$ & $\begin{array}{l}4 \times 25 \mathrm{M} \\
4 \times 25 \mathrm{M} \\
4 \times 25 \mathrm{M} \\
4 \times 25 \mathrm{M}\end{array}$ & 3 & 4 & $\begin{array}{l}\text { - Lama istirahat } \\
\text { setiap set dan } \\
\text { repitisi tidak } \\
\text { dibatasi, cukup } \\
\text { sampai oksigen } \\
\text { dan tenaga } \\
\text { perenang } \\
\text { kembali. } \\
\text { - Setelah latihan } \\
\text { penutupan di } \\
\text { akhiri dengan } \\
\text { evaluasi }\end{array}$ \\
\hline & $\begin{array}{l}\text { - Latihan Inti } \\
\text { - Latihan } \\
\text { Penutup }\end{array}$ & $\begin{array}{l}\text { - Swim gaya bebas } \\
\text { - Swimdown }\end{array}$ & $2 \times 100 M$ & & & \\
\hline
\end{tabular}

